This item was submitted to Loughborough's Research Repository by the author.

Items in Figshare are protected by copyright, with all rights reserved, unless otherwise indicated.

\title{
Information systems architecture for fire emergency response
}

PLEASE CITE THE PUBLISHED VERSION

https://doi.org/10.1108/JEIM-12-2015-0120

PUBLISHER

(C) Emerald

VERSION

AM (Accepted Manuscript)

\section{PUBLISHER STATEMENT}

This work is made available according to the conditions of the Creative Commons Attribution-NonCommercialNoDerivatives 4.0 International (CC BY-NC-ND 4.0) licence. Full details of this licence are available at: https://creativecommons.org/licenses/by-nc-nd/4.0/

\section{LICENCE}

CC BY-NC-ND 4.0

\section{REPOSITORY RECORD}

Prasanna, Raj, Lili Yang, Malcolm King, and Thomas J. Huggins. 2019. "Information Systems Architecture for Fire Emergency Response". figshare. https://hdl.handle.net/2134/23052. 


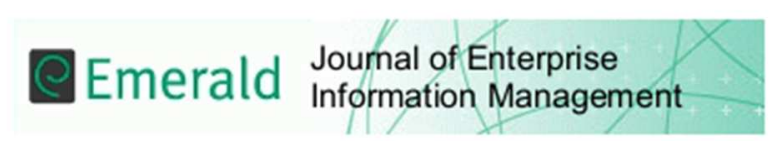

\section{Information Systems Architecture for Fire Emergency Response}

\begin{tabular}{|r|l|}
\hline Journal: & Journal of Enterprise Information Management \\
\hline Manuscript ID & JEIM-12-2015-0120.R3 \\
\hline Manuscript Type: & Research Article \\
\hline Keywords: & $\begin{array}{l}\text { information systems, emergency response, fire, prototype, information } \\
\text { systems architecture }\end{array}$ \\
\hline \multicolumn{2}{|l}{} \\
\hline
\end{tabular}

SCHOLARONE ${ }^{\prime \prime}$

Manuscripts 


\title{
Information Systems Architecture for Fire Emergency Response
}

\begin{abstract}
Purpose

There has been a lack of meaningful information systems architecture, which comprehensively conceptualise the essential components and functionality of an information system for fire emergency response addressing needs of different job roles. This study proposes a comprehensive information systems architecture which would best support four of the key fire-fighter job roles.

Design

The study has built on the outcomes of two previous preliminary studies on information and human-computer interaction needs of core fire fighter job roles. Scenario based action research was conducted with fire fighters in a range of roles, to evaluate human computer interaction needs while using various technology platforms.
\end{abstract}

\section{Findings}

Several key themes were identified and led us to propose several layers of an integrated architecture, their composition and interactions.

\section{Research limitations}

The selected fire scenarios may not represent every type of fire expected in high risk built environments.

\section{Practical implications}

The current paper represents a shared discussion among end users, system architects and designers, to understand and improve essential components. It, therefore, provides a reference point for the development of an information system architecture for fire emergency response.

\section{Originality}

The proposed information system architecture is novel because it outlines specific architectural elements required to meet the specific situation awareness needs of four of the key firefighters job roles. 


\section{Introduction}

Compared to most other disaster related jobs such as emergency operations centre personnel, ambulance services and medical rescues, fire fighters face comparatively stressful and lifethreatening environments where they have very little time to make a life and death decision (Sha et al.,2006). Such contextual differences create a unique set of needs and requirements for the frontline fire fighters (Prasanna, 2010). Although there has been several attempts to design or develop information systems supporting fire emergency response it has been a challenge to conceptualise the essential components of an information system (IS) for fire emergency response (ER) addressing needs of different job roles and the functionality of such an IS.

There appears to be very little literature on the higher-level systems architecture of an IS supporting different fire fighter job roles having different information needs which is well understood by both the owners of the system as well as the systems architects. The lack of understandings between system architects, firefighters and fire and rescue service (FRS) could become one of the major constraints during IS development. The lack of processes and dialogue between these groups is, in turn, likely to slow down the progress of implementing fire ER support systems. In effect, a lack of dialogue and shared processes may mean ISs are being developed only to be rejected by end users. Regarding psychology of change in organisations, this represents simply pushing changes onto end users, instead of informing changes according to user needs (see Clegg and Walsh, 2004).

As a response to this situation, the remainder of this paper is organised into five main sections. The first of these sections outlines a brief review of relevant literature, and the subsequent section outlines the overarching research approach and details of adopted methods. Then this paper presents the results which include identified strengths of the proposed ISA. This is followed by a section explaining the components and functionality of layers of the proposed ISA including its applicability and validation. The last section of this paper outlines the contribution of this study to ISA and emergency management literature, followed by the limitations and potentials for further research.

\section{Literature Review}

There have been several attempts to develop Information Systems Architectures (ISAs) for exclusively supporting ER. For example, Madey et al. (2006) developed a wireless phone 
based ISA to provide traffic forecasts and emergency alerts for engineering, public safety and ER personnel. The scope of this architecture remains limited to the technological capabilities of mobile phones. Other examples include "WORKPAD" (de Leoni et al., 2007), which is a layered communication architecture to support decision making during ER operations. This architecture has a Mobile Ad-hoc Network (MANET) based data storage \& communication layer, a middleware layer for the management of various emergency related dynamic processes, and user layers which support two types of users and their interaction with the system. Although the MANET architecture aims to support needs of the operators who were in the field during disasters, there is no evidence that it has addressed the distinct needs of different types of responders.

German researchers, Meissner et al. (2006) of Fraunhofer-Gesellschaft (see FraunhoferGesellschaft, 2007) presented an integrated mobile information and communication systems architecture for ER operations: Mobile Information and Communication System for Public Safety Organisations (MIKoBOS). This architecture supports reliable data communications within an emergency site and between an emergency site and headquarters. Meissner et al. (2006) were focused on some common needs of emergency management personnel including: emergency personnel working at the command centres; emergency operation commanders working inside vehicles located at an incident; and frontline responders who may be mobile and located anywhere within an incident scene. The MIKoBOS architecture was developed by comparing technologies for communicating within networks of different user types (Meissner, et al., 2006). It also reflected actual requirements of end users working in emergency related domains. However, this architecture addresses generic emergency situations. It is, therefore, unlikely to comprehensively address ISA requirements specific to a particular type of emergency, being responded to by a particular type of emergency service.

There are also ISAs that focus on supporting a particular type of emergency condition or domain (Kwan \& Lee, 2005; Hwang et al., 2007; Lorincz et al., 2004). This includes ISAs for supporting fire emergencies. Examples include the work of Wilson et al. (2005) and Wilson et al. (2007) on the Fire project, Jiang et al. (2004a) on the Siren project, Jiang et al. (2004b) on Large Displays for Incident Commanders (ICs), Klann (2008) on the LifeNet project, May et al. (2014) on potential benefits of wireless networks for tunnel fire response, Roh (2015) on integrating technologies supporting decision making using the transmitted information, and Scholz et al. (2013) on a system supporting frontline fire fighter communications. These examples represent significant efforts to develop firefighter related 
ISs. However, and although all this work looked at systems supporting fire ER in built environments, none of it focused on supporting the specific response operations of the Fire and Rescue Service (FRS), through the development of an overarching IS architecture.

Our own search for recent developments on ISAs supporting fire ER is complemented by a systematic literature review by Dorasamy et al. (2013), which explored knowledgedriven information systems in support of emergency management in last two decades. Dorasamy et al. (2013) identified 51 significant pieces of emergency management information systems research. Much of this research was presented at highly ranked IS conferences, including the Americas Conference on Information Systems, and published in prominent journals such as Technological Forecasting and Social Change, Journal of Information Technology Theory and Application, Management Information Systems Quarterly, and Disaster Prevention and Management. The majority of the studies reviewed by Dorasamy et al. (2013) were published in the well-known crisis informatics journal, International Journal of Information Systems for Crisis Response and Management and presented at its annual Information Systems for Crisis Response and Management conference. Close examination of 51 systems considered by Dorasamy et al. (2013) clearly indicate that except for SafetyNet (n.d.), which is the system associated with the ISA proposed in the current paper, there had been no other significant, directly relevant research in this area as at 2013. In particular Dorasamy et al. (2013) reported no other significant research regarding information systems for supporting various firefighting job roles.

When considering technology platforms proposed in last two decades, it appears that the FireGrid Project (Upadhyay et al., 2008) and the hybrid architecture of Nguyen et al. (2015) are the only substantial architectures exclusively designed for supporting fire ER in built environments. The high-level architecture proposed for the FireGrid includes sample components along with data and control connections. This architecture integrates various technologies in a distributed design. However, and although the FireGrid architecture recognises a need to use diverse technology to capture contextual information, it does not identify the technological diversity required for the successful presentation of information to various types of firefighters. Furthermore, this architecture does not reflect how differences in firefighter roles, behaviours and working contexts create demands for different Human Computer Interaction (HCI). Therefore, the proposed FireGrid architecture does not appear capable of addressing the distinct needs of different firefighter job roles. 
A more recent study conducted by Nguyen et al. (2015) in Germany proposed a hybrid architecture for firefighters and examined how different smart technologies could be coupled to support fire fighters. However, this latter study does not substantially address the research and conceptual gap concerning ISAs for fire ER. Nguyen et al. (2015) appear to have been driven by traditional software engineering techniques. As a result, their study has not clearly identified the unique information needs of different fire fighter job roles.

There are three key limitations in the wider literature related to ER ISAs. Firstly, most of the proposed architectures are technologically biased and only focus on common needs held among a broad range of emergency responders. Although there have been some efforts to support fire ER specifically, these efforts appear to focus on a selection of common needs. They do not address the needs of different key fire fighter job roles experienced while responding to a large incident. Most of the architectures proposed are therefore not comprehensive enough to cover the full scope of expectations of the fire and rescue hierarchy during fire ER in a built environment. At the time of writing, there appears to be very little evidence of an existing ISA that supports the diverse needs of different firefighter job roles.

Secondly, and even more importantly, there is a very little literature on the systems architecture of an IS for fire ER, which is well understood by both the end users of the system as well as system architects. Instead, most of the available ISAs are only capable of communicating system characteristics to IS architects and developers. Although there are a few highly sophisticated and technically advanced ISAs for supporting fire emergencies, the development of such architectures appears to have excluded communication with the actual end-users, especially during very early stages of systems design such as requirements gathering. It is critically important to review the architecture of an IS, to reduce the cost of mistakes and to find and fix architectural problems as early as possible. Architecture review is a proven, cost-effective way of reducing project costs and the chances of project failure. This helps systems designers to identify issues and recognise areas for improvement (Microsoft, 2015). As part of this process, especially when designing a complex system for stressful environments such as fire emergencies, it is essential to communicate the intended system and its architecture to, and get the feedback from, the owners of the system. In this case, the owners of the system are fire fighters with a specific range of different job roles.

Finally, there has been a lack of meaningful ISAs, which comprehensively address the varying Situation Awareness (SA) needs of different fire fighter job roles. For many decades, Situation Awareness (SA) has been identified as one of the critical concepts to be considered 
when designing information systems supporting end-users working under stressful environments. Salmon et al. (2016) argued that systems which are not capable of enhancing SA lead to decision making failure causing huge economic and human losses. Endsley et al. (2003) identified eight possible factors that lead to situation awareness (SA) failures and named them SA Demons. Understanding the impact of these SA demons and efforts of minimising such impacts in the process of design and development of a system is an important part of the implementation.

To make things worse, there has been very little evidence to substantiate the success of any IS implemented for supporting fire ER. A lack of available technology platforms for exclusively supporting fire fighters is highlighted in one of the recent studies into fire fighter acceptance of new technology platforms (Yang et al., 2013). In this research Yang et al. (2013) concluded that firefighters fear using technology as they are worried about the reliability of the existing systems and have procrastinated in adopting them. This clearly indicates that there is a significant lack of current literature outlining appropriate technology architectures for supporting unique and individual information requirements of different fire fighter job roles when responding to fire emergencies.

To start overcoming this above described gap in the current literature, this study aimed to define an Information Systems Architecture (ISA) to support firefighters' response to fires in large scale built environments. This ISA is based on the comprehensive needs of potential end users. We aimed to develop definitions which were clearly understood by the system's potential end users, as well as by the system's designers and architects. Importantly, the architecture would not be limited to relying on one particular technology or one established set of technologies.

The "Owner's View" of an ISA

The current approach to defining an ISA was based on the work of Zachman (1987) and Sowa and Zachman (1992). Zachman (1987) made an analogy between traditional building architecture and information technology architectures which led them to categorise six different views or perspectives: planner's view of size, shape, relationships and intent; owner's view drawn by the architect; designer's view drawn by the architect; contractor's view drawn by the contractor; subcontractor's view drawn by the sub-contractor; and finally the enterprise view, which represents the physical makeup of an architecture. 
These perspectives are associated with three types of description (Zachman, 1987) that characterise each view by categories of data, function and network and descriptive dimensions of what, how and where descriptions (Zachman, 1987). In total, the Zachman (1987) taxonomy forms a six by three ISA matrix. Rows represent the six perspectives and columns represent the three types of description. Sowa and Zachman (1992) went on to add three more types of descriptions: people, time and motivation, which correspond to questions of who, when and why. Figure 1 represents the latter, extended ISA framework.

\begin{tabular}{|c|c|c|c|c|c|c|}
\hline & $\begin{array}{l}\text { DATA } \\
\text { What }\end{array}$ & $\begin{array}{c}\text { FUNCTION } \\
\text { How }\end{array}$ & $\begin{array}{l}\text { NETWORK } \\
\text { Where }\end{array}$ & $\begin{array}{l}\text { PEOPLE } \\
\text { Who }\end{array}$ & $\begin{array}{l}\text { TIME } \\
\text { When }\end{array}$ & $\begin{array}{l}\text { MOTIVATION } \\
\text { Why }\end{array}$ \\
\hline $\begin{array}{l}\text { Objective/Scope } \\
\text { (contextual) } \\
\text { Role: Planner }\end{array}$ & $\begin{array}{l}\text { List of things } \\
\text { important in } \\
\text { the business }\end{array}$ & $\begin{array}{l}\text { List of } \\
\text { Business } \\
\text { Processes }\end{array}$ & $\begin{array}{l}\text { List of } \\
\text { Business } \\
\text { Locations }\end{array}$ & $\begin{array}{l}\text { List of } \\
\text { Important } \\
\text { Organizations }\end{array}$ & $\begin{array}{l}\text { List of } \\
\text { Events }\end{array}$ & $\begin{array}{l}\text { List of } \\
\text { Business Goal } \\
\text { \&Strategies }\end{array}$ \\
\hline $\begin{array}{l}\text { Enterprise Model } \\
\text { (conceptual) } \\
\text { Role: Owner }\end{array}$ & $\begin{array}{l}\text { Conceptual } \\
\text { Data/ } \\
\text { Object Model }\end{array}$ & $\begin{array}{l}\text { Business } \\
\text { Process } \\
\text { Model }\end{array}$ & $\begin{array}{l}\text { Business } \\
\text { Logistics } \\
\text { System }\end{array}$ & $\begin{array}{l}\text { Work } \\
\text { Flow } \\
\text { Model }\end{array}$ & $\begin{array}{l}\text { Master } \\
\text { Schedule }\end{array}$ & $\begin{array}{l}\text { Business } \\
\text { Plan }\end{array}$ \\
\hline $\begin{array}{l}\text { System Model } \\
\text { (logical) } \\
\text { Role: Designer }\end{array}$ & $\begin{array}{l}\text { Logical } \\
\text { Data } \\
\text { Model }\end{array}$ & $\begin{array}{l}\text { System } \\
\text { Architecture } \\
\text { Model }\end{array}$ & $\begin{array}{l}\text { Distributed } \\
\text { Systems } \\
\text { Architecture }\end{array}$ & $\begin{array}{l}\text { Human } \\
\text { Interface } \\
\text { Architecture }\end{array}$ & $\begin{array}{l}\text { Processing } \\
\text { Structure }\end{array}$ & $\begin{array}{l}\text { Business } \\
\text { Rule } \\
\text { Model }\end{array}$ \\
\hline $\begin{array}{l}\text { Technological Model } \\
\text { (physical) } \\
\text { Role: Builder }\end{array}$ & $\begin{array}{l}\text { Physical } \\
\text { Data/Class } \\
\text { Model }\end{array}$ & $\begin{array}{l}\text { Technology } \\
\text { Design } \\
\text { Model }\end{array}$ & $\begin{array}{l}\text { Technology } \\
\text { Architecture }\end{array}$ & $\begin{array}{l}\text { Presentation } \\
\text { Architecture }\end{array}$ & $\begin{array}{l}\text { Control } \\
\text { Structure }\end{array}$ & $\begin{array}{l}\text { Rule } \\
\text { Design }\end{array}$ \\
\hline $\begin{array}{l}\text { Detailed } \\
\text { Representation } \\
\text { (out of context) } \\
\text { Role: Programmer }\end{array}$ & $\begin{array}{l}\text { Data } \\
\text { Definition }\end{array}$ & Program & $\begin{array}{l}\text { Network } \\
\text { Architecture }\end{array}$ & $\begin{array}{l}\text { Security } \\
\text { Architecture }\end{array}$ & $\begin{array}{l}\text { Timing } \\
\text { Definition }\end{array}$ & $\begin{array}{l}\text { Rule } \\
\text { Speculation }\end{array}$ \\
\hline $\begin{array}{l}\text { Functioning } \\
\text { Enterprise } \\
\text { Role: User }\end{array}$ & $\begin{array}{l}\text { Usable } \\
\text { Data }\end{array}$ & $\begin{array}{l}\text { Working } \\
\text { Function }\end{array}$ & $\begin{array}{l}\text { Usable } \\
\text { Network }\end{array}$ & $\begin{array}{l}\text { Functioning } \\
\text { Organization }\end{array}$ & $\begin{array}{l}\text { Implemented } \\
\text { Schedule }\end{array}$ & $\begin{array}{l}\text { Working } \\
\text { Strategy }\end{array}$ \\
\hline
\end{tabular}

Figure 1: Framework of Information Systems Architecture

An extensive understanding of the fire emergency context was gained in this study through user centred and action research based interactions (see Hayes, 2011) with practising firefighters. This approach most immediately corresponded to the planner's view of an ISA framework (Zachman, 1987), while identifying the basic purpose of an IS in the minds of firefighters. However, it became evident that a planner's view was not detailed enough to have a comprehensive understanding of the IS components for supporting firefighters. According to Zachman (1987), the owner's view is made up of architect's drawings depicting final structures. These structures are shown from the perspective of an owner who will have to incorporate them into the daily routines of their business regarding relationships between business entities and processes. This set of drawings could also be referred to as an end-user's 
view. They correspond to an enterprise model or a conceptual architecture of an information system, to align with the overall business model of an organisation. This is how our initial contextual understanding laid a foundation to propose a comprehensive, "owner's view". This was achieved by providing a comprehensive conceptual IS architecture which was clearly understood by firefighters, FRS, and the architects and designers of a fire emergency IS.

\section{Methodology}

Pre-existing literature summarised in the introduction section, together with preliminary interviews with fire and rescue service members, have suggested that many IS architectures fail after neglecting to identify comprehensive end user requirements and failing to specify interfaces that will meet those requirements. To overcome such profound limitations, the current research has built on the outcomes of two preliminary studies conducted over a period of four years.

\section{First Preliminary Study}

The first of the two preliminary studies produced a set of the comprehensive and validated information needs for core members of the UK Fire and Rescue Service Incident Command Hierarchy, namely: 1) Incident Commanders (IC), 2) Sector Commander (SC), 3) Breathing Apparatus Entry Control Officers (BAECOs), and 4) Breathing Apparatus Wearers (BA Wearers). In this iterative study, acquisition of the information needs of firefighters was driven by a goal oriented cognitive task analysis tool: Goal Directed Information Analysis (GDIA) which was exclusively developed for the first preliminary study after considering many other cognitive task analysis tools (Yang et al., 2014). This study included face-to-face semi-structured interviews and brainstorming sessions with firefighters, together with observations of related training, amounting to over 1,000 hours of contact with potential end users. At the end of the study a comprehensive set of information requirements for the four core job roles of the UK FRSs was obtained in the form of 310 GDI diagrams which illustrates the link between Goals-Decisions and Information needs for each fire fighter job role. 
Second Preliminary study

Having considered the comprehensive information needs identified in the first preliminary study, the second study produced a validated set of human-computer interfaces. These interfaces were designed to address human-computer interaction requirements for the core job roles outlined above (Prasanna et al., 2013).

The interfaces proposed were designed and developed with the support of Windows-based software prototyping tools, GUI Design Studio Version 2.0, and Adobe Flash. These interfaces form the basis of the first step of an evolutionary development of a fully-fledged IS supporting firefighting response. These interfaces are capable of representing dynamic incidents, changing across time and space. Adobe flash software was chosen to embed high level dynamism in the interfaces. This allowed the interfaces to simulate the movement of firefighters in a building, data entry interfaces with direct manipulation, and dynamically appearing alarms. The design and development of the software prototypes was followed by a series of prototype demonstration sessions with potential end-users, to understand the appropriateness and usefulness of the proposed software prototype for supporting fire ER.

\section{Current Action Research}

Study The current paper concerns scenario based action research that was conducted to evaluate the performance of human-computer interfaces developed in the second preliminary study when those interfaces were deployed under different available technology platforms. Action research was considered an appropriate approach to evaluating these interfaces because, according to Hult and Lennung (1980), this approach assists in practical problem solving while simultaneously expanding scientific knowledge. This study was performed collaboratively with members of the FRS being studied, through iterative cycles of research which led towards an incrementally improved understanding of their specific situation.

The current research incorporated feedback from various direct and indirect stakeholders, including members of the FRS directly attached to the fire incident command hierarchy during a fire emergency and other emergency services: Police, the Ambulance and Hospital Service.

The action research included deployment of human-computer interfaces developed and validated during the preliminary research outlined above. These interfaces were deployed alongside a variety of technologies, within a range of operational contexts: at incident sites; 
in fire engines which had been deployed near incidents; with mobile fire fighter personnel; in temporary incident command units near an incident; control room of an incident building; in a fire and rescue regional incident command centre; in a police command centre; at a local hospital; and in a local ambulance control centre. Stakeholders were asked to use the interfaces across a variety of technology platforms. They were asked to use these interfaces to support fire incident response event in a simulated setting affected by a predefined fire scenario.

\section{Evaluation Walkthrough and Evaluation Workshop}

Participants in this scenario were then asked to comment on their experience of using the interfaces as part of different communication and information technologies. They were also asked to compare interface performance between variations in the technology provided alongside those interfaces. Although all variations involved existing software and hardware technologies, participants were also asked to comment on new technology adaptations being piloted during the study. Interface evaluations were conducted in both low demand and simulated stress environments. Evaluation workshops and evaluation walkthrough were identified as the most suitable methodologies for evaluation the use of prototype interfaces in low demand contexts, because of their participatory and less demanding nature. User testing in a simulated environment provided the setting for evaluation in a more demanding environment. An evaluation walkthrough is process, where a member of the design team goes step by step through a system while recording reactions from participants. An evaluation workshop instead asks user representatives to use the system to accomplish a set of tasks observed by designers. Both processes provide an detailed description of how a proposed system design could be used for different tasks under different circumstances (Maguire, 2001). According to Stanton et al. (2005), both processes can provide a powerful assessment of design concepts.

During our preliminary workshops and walkthrough sessions, participants were encouraged to ask any questions they had. They were also asked to comment on the usability and functionality of the interfaces presented as part of different technology platforms. All comments from session participants were recorded and collated in a data file. As stated above, it was acknowledged that the workshop evaluations did not provide genuine usability 
testing. Likewise, walkthrough evaluations do not usually include the kinds of stressors experienced during actual emergency response operations.

\section{Field Testing the Prototype}

User testing in a simulated environment was chosen to overcome the limitation of the prototype evaluation sessions by situating the simulation prototype in a well-established training environment in the Leicestershire FRS Training School at Loughborough, UK. All principal categories of emergency responders participated within this training environment. Information was shared between various interfaces by using the range of proven telecommunication technologies outlined in Table 1 . These technologies were incorporated under different communication parameters, to reflect the scenario being simulated.

An incident scenario was designed to feature a well-known shopping centre. The shopping centre was assumed to be on fire, with a number of shopping centre staff and customers trapped inside. This scenario was completed within 50 minutes before being repeated with three different sets of participants. The process was repeated six times in total, on different dates and under various technology platform arrangements, including different technology and communication arrangements. Participants' interactions with the interfaces were recorded by several video recorders, during all scenario sessions. Video recordings were transcribed into text-based reports once all training had been completed. Transcripts were then categorised, coded, and organised into a data file for analysis.

Participants were also asked to complete a questionnaire to record their experiences. The questionnaire was split into two sections. The first section covered how successfully the participants could interact with the prototype and asked them to measure the success of their interactions on a scale of 1 to 10 . The second section measured how satisfied or dissatisfied participants were with both the appearance and functionality of the IS. All answers to the questionnaire were summarised and later combined with the analysis of data from the workshop, walkthrough, and training sessions. 


\section{Results}

Data gathered from this study of human-computer interfaces as part of varying technology platforms highlighted the benefits of taking an "owner's view” from early in the development of a complex IS. Data analysis produced key themes, describing essential requirements that were expected from an ISA and also transparently understood by both IS owners and designers. Comments from nearly 80 percent of stakeholder and participant feedback clearly suggested that the proposed information output screens would improve decision making capacity and operational effectiveness, but only if the ISA:

1. Consists of a network of technologies to capture data from the incident environment;

2. Consists of a mechanism to process data;

3. Is capable of making unprocessed data more meaningful by organisation or classification; and

4. Can cater for individual needs and display different categories of information in a way which is meaningful for those individuals.

\section{Overall Strengths of the Prototype ISA}

A range of sub-themes regarding expected functionality and components of the proposed ISA were also obtained during piloting. Principal themes concerned overall strengths of the ISA characteristics. End user feedback from seventeen out of nineteen evaluation sessions confirmed the overall success of the mock-ups proposed. Feedback also reflected that the mock-up prototypes had been considered a genuine representation of an IS. Participants in all job roles showed that they accepted the mock-ups as a system of human-computer interfaces to support their ER operations. More than 80 percent of participants mentioned that the proposed interfaces matched with their expectations of an ideal system. They considered that the mock-ups presented information in a way which would support real decision making.

Comments from nearly 90 percent of feedback on IC and SC prototypes suggested that the proposed information output screens would improve decision making capacity and operational effectiveness. This feedback showed that ICs preferred to use the summarised information screens more frequently than the SCs. The graphical screens, showing in depth details of internal and external context, still appeared useful to a number of SCs. The simple and rapid combination of graphical information layers, delivering comprehensive decision making support, appeared to be appreciated by most participants. Participants also 
highlighted how these interfaces could improve their forecasting capabilities. Other feedback suggested that the efficiency of proposed interfaces created extra time to extend decision making cycles.

More than 75 percent of participants in the BAECO and BA Wearer sessions gave a positive response to the prototypes. They described how interfaces deployed inside fire engines can help them to prepare physically and mentally to carry out operations while still en-route. More than 50 percent of positive feedback also suggested that interfaces for BAECO and BA Wearers could help the FRS to modify existing fire and rescue procedures, which participants appeared to find complex and/or lacking effectiveness.

Feedback from more than 80 percent of participants representing IC, SC and BAECO roles highlighted the importance of alarms for aiding successful decision making. It seemed that appropriate alarms would allow the ICs and SCs to better balance attention amongst the many activities and events occurring during an incident. Feedback also suggested that alarms could allow BA Wearers to become more mentally and physically flexible during operations. The alarms appeared to be able to minimise stress on the BA Wearers' basic senses like ears and eyes. Apart from providing basic alarms on the use of resources, feedback highlighted the importance of providing alarms for BA navigation, to increase the physical flexibility of BA Wearers.

Participants from sixteen evaluation sessions, including a group of third party specialists, stated that it was vital to have input interfaces which were both simple and userfriendly. It seemed that these end user data input screens would encourage end users to input their own information. According to the participants, inappropriate data input screens could lead to output screens being seen as inaccurate due to insufficient human data input and an over-reliance on non-human sensors. This appeared related to a loss of trust in the system, amongst many fire fighters who were not ready to rely on completely non-human sensors. Feedback from participants in nine sessions suggested that the prototype data input screens could help address these issues, by facilitating reliable human data input. The following section discusses these findings and other details about surrounding literature, to propose a new set of information system layers. 


\section{Research Synthesis: Information System Layers}

With reference to the themes and other results outlined above, we propose an "owner's view" of the ISA. This view is capable of delivering on the requirements outlined above, by identifying requirements and supporting information needs during a fire emergency response. To address the architectural needs outlined above, we propose an ISA consisting of four layers:

1. The Data Capture and Networks Layer of the architecture, to capture data from various information sources and provide communication between information sources and other components of the architecture.

2. The Data Manipulation Layer, to provide services that add value to data initially captured from various sources.

3. The Function Modules Layer, to organise information for common functionalities which different end users expect.

4. The Human Computer Interaction Layer, to manage the functionality of various humancomputer interfaces, supporting different firefighter jobs through a range of devices.

\section{Data Capture and Networks Layer}

This layer is effectively a communication infrastructure for the IS. When considering the various needs of firefighters, both electro-mechanical and human sources are required to capture data, including data input from firefighters with very different roles. It is crucial to capture information needs from many different types of information sources located in and around incident premises. It is also as vital to maintain communication among: contextual information capturing devices; firefighters located inside and outside incident premises; display devices inside the fire engines and various locations within incident premises; the FRS control room; fire stations; other response services such as ambulance, police and the local government; and third parties providing weather, media and traffic information.

The current ISA pilot shows how there was no single communication technology to meet the requirements of all end users. Instead, network redundancy seems to be an important issue raised by participants. It would, therefore, be most appropriate to use a network architecture that simultaneously supports multiple communication technologies. 


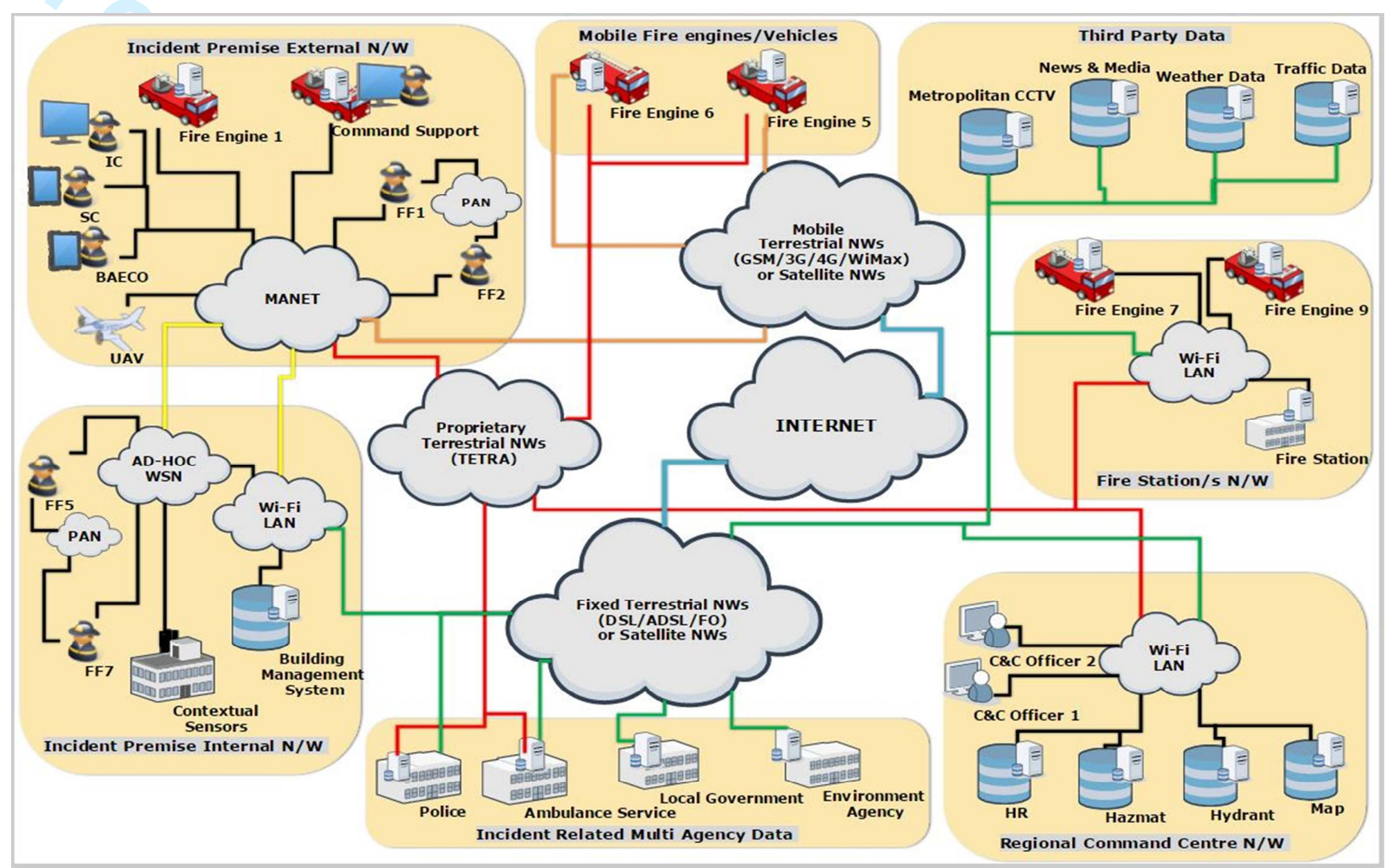

Figure 2: Data Capture and Networks Layer 
Integrating various technologies into a single platform which allows them to be used both flexibly and interchangeably mean that various communication alternatives can complement each other. When one network is unavailable, the system can switch to use another available option. Preferably, the ISA will automatically switch from unavailable to available technologies according to predefined policies (see Meissner et al., 2006). This will help guarantee the availability of communications without having to pay for the provision of contingent services when they are not actually used. Based on the considerations outlined, the current paper proposes a high-level architectural layout for the data capture and networks layer as elaborated in figure 2. In addition, Table 1 summarises components and suitable technologies for implementing each component across multiple locations.

[Table 1. Components and Technologies for Data Capture and Networks Layer]

\section{Data Manipulation Layer}

Data captured from the Data Capture and Networks layers are passed up to this layer, which provides support services to carry out common data manipulations such as storing, filtering and processing. This means that more value-added data can be passed on from one layer to another, to carry out higher level functions unique to fire ER. For these purposes, the current research proposes three main considerations: data management; data fusion and the method/model base.

The current paper has highlighted how fire ER information systems should primarily enhance fire fighters' awareness of their operational situation. Data fusion within an IS needs to be executed in a way which promotes such awareness. Salerno et al. (2004) discussed the need for data fusion for achieving situational awareness in multisensory data capturing contexts. They outlined more than thirty fusion models that had already been proposed, and which may have had some relevance for the proposed ISA.

None of these data fusion models appears to have been as influential as the Joint Directors of Laboratories (JDL) model, outlined by Hall and Llinas (1997). Salerno et al. (2004) suggested that the JDL model provided the most appropriate way to use data fusion for complementing the situation awareness model from Endsley (1995), in complex domains. The JDL model outlines data fusion in three increasing levels of inference (Hall and Llinas, 1997): Object Assessment, to combine location and parametric data to identify and represent individual objects; Situation Refinement, to develop a description of current relationships 
among current objects and events in the operational environment; and Impact Assessment, to project situation progress into the future. Blasch et al. (2006) identified that outputs from these levels of inference corresponded to Level 1 (SA perception), 2 (SA comprehension) and 3 (SA projection) components of the Endsley (1995) situation awareness model.

The current research indicates a need for ad hoc sensor networks with a variety of contextual and location tracking sensors. These sensor networks will need to process large amounts of heterogeneous sensory data and information from spatially dispersed sources. Sensory data and other information are usually processed centrally (Maris and Pavlin, 2006). However, central processing can suffer from inadequate communication and processing capacities. Central processing is also vulnerable to single point failures, because of the absence of redundancy. Also, centralised approaches to fusion might not be well suited for dynamic systems operating in highly fluid and challenging environments. This is because central processing depends on centralised reasoning about the states of the fusion system itself. This has the potential to result in a massive flow of information and the need for additional processing (Pavlin et al., 2004), resulting in bottlenecks in the flow of information.

We, therefore, recommend distributed, rather than centralised, data fusion. An appropriately distributed fusion system would be able to adapt to operational situations without human intervention. IS modules should form fusion systems with other relevant modules which can calculate resource allocation for sensing and processing capacity (Pavlin et al., 2007). To cope with such complex functionality in a systematic way, this study proposes a multi-agent system (see Wooldridge, 2009) where each agent takes care of partial fusion, as defined by Maris and Pavlin (2006).

Considering data processing capabilities of modern data sensor nodes, we propose a tiered approach to data fusion, as outlined by Mullen (2006), Chong and Kumar (2003) and Pavlin et al. (2004). A tiered fusion network should consist of two types of agents: 1) the sensor agents, consisting of both physical and human sensors; and 2) the fusion agents, receiving input from sensor agents for further data fusion. By adopting partial data fusion, the proposed Data Fusion service layer should be able to combine support from various sensor agents and fusion agents, to fuse data captured from various data sources and store them in the fusion database. It is anticipated that sensor and fusion agents connected in this tiered approach to data fusion will be able to fuse data into all three levels of inference outlined in the JDL fusion model. 
As outlined above, this use of the JDL model forms a systematic approach to supporting the situation awareness of end-users. However, the proposed ISA cannot meet Level 2 and Level 3 situation awareness needs unless data fusion is supported by an appropriate Methods/Models Base, to store supporting methods, models and procedures. This base needs to provide support for: phrasing and cleaning data to increase salience; alerting end users to new knowledge; and controlling overall functionality of the system, for example, speech recognition to control the Head Mounted Display (HMD). Other relevant services could include Kalman Filters, Alpha Beta Filters, Covariance Error Estimation and expert build models such as Computational Fluid Dynamics (CFD) models for fire, cloud or hazardous gas propagation - depending on identified needs.

Database management can be particularly challenging in an IS which needs to deal with large and varied data including images, signal data, vectors, textural data, and both incoming and rapid retrieval data rates (Hall and Llinas, 1997). As outlined above, data managed by an IS for fire ER have many of these characteristics. A Data Management service is required to facilitate access to, and management of, data fusion databases and all other supporting databases. This includes data retrieval, storage, archiving, compression, queries, and data protection. The type of data stored in these databases can be dynamic, static or historical. These databases are usually highly distributed and can be located at a number of sites, from the actual incident to off-site facilities, including facilities provided by third parties.

\section{Function Modules Layer}

Modules in this layer carry out the processing required for a functional HCI Layer by combining a number of basic services. The Function Modules Layer represents a transparent ISA layer for end users who interact with the system via the HCI. It should, therefore, be able to process data in a way which improves the usefulness of information being delivered. Responsive ISA design means that data processed within the Function Modules layer is presented at the HCI Layer, according to the unique requirements of end users with various job roles.

Both preliminary research and the current IS pilot have indicated a need for modules that manage: physical and human resources; sectors and cordons; hierarchy and job roles; and location tracking and navigation. Further modules are required to process geographical data, monitor variations in the operational context, input other data, and generate alarms, logs and 
reports. End users will often need combinations of these modules to meet ER demands. For example, monitoring the spread of a chemical plume may require the processed output of both context monitoring and geographic modules. It is, therefore, vital that the entire Function Modules Layer is designed so that each module can communicate with any other main or sub-module required for operational tasks.

\section{Human-Computer Interaction (HCI) Layer}

Preliminary research indicated that the requirements for four particular job roles would directly or indirectly address the needs of other incident command hierarchy members. The HCI layer of the proposed ISA has therefore been designed to accommodate four main job roles: an IC, a SC, a BAECO and BA Wearer. Modules for each job role need to be implemented with technology which ensures human access to required interfaces. For example, an HCI module for the IC job role should consist of a dashboard, a black box and many other interfaces which are capable of displaying information for supporting perception, comprehension and projection.

In addition to the four main job roles, the proposed ISA will need to provide operational access to the IS for all other members of the IC hierarchy. As outlined by Prasanna et al. (2007), this means that the HCI layer needs to include human-computer interfaces that support a range of other roles. For example, given similarities in work behaviour, mobility and the working environment, the HCI module proposed for IC's would also suit Operational Commanders. The HCI module for SC's also appears to suit other functional and operational SC, Crew Commander and Safety Officer roles. Further customisation may be required when designing the human-computer interfaces for these other job roles. Likewise, as observed during the current research, it will be important to provide online access to additional members who are directly or indirectly linked to the incident command hierarchy during a response operation. This includes Command Support (CS) team members and other officers working from a control room.

Members of the CS team provide the bulk of information management support to an incident command team. These members play a human sensor role that can input important information to the system. Officers at the control room are also important for fire detection and initial resource deployment. Feedback received during the current research also indicated that if the officers at a control room can continuously monitor an operation, this would further 
enhance the response operation on site. It is, therefore, important that the HCI Layer also has modules which can support each of these job roles. In sum, an HCI layer for comprehensive fire ER should include the following modules: IC/Operations Commander; SCs (Functional and Operational); Crew Commanders and Safety Officers; BAECOs; BA Wearers and other frontline Firefighters; CS Officers; and officers at the control room. All remaining firefighter job roles are assumed to align with these categories for the purposes of HCI module design.

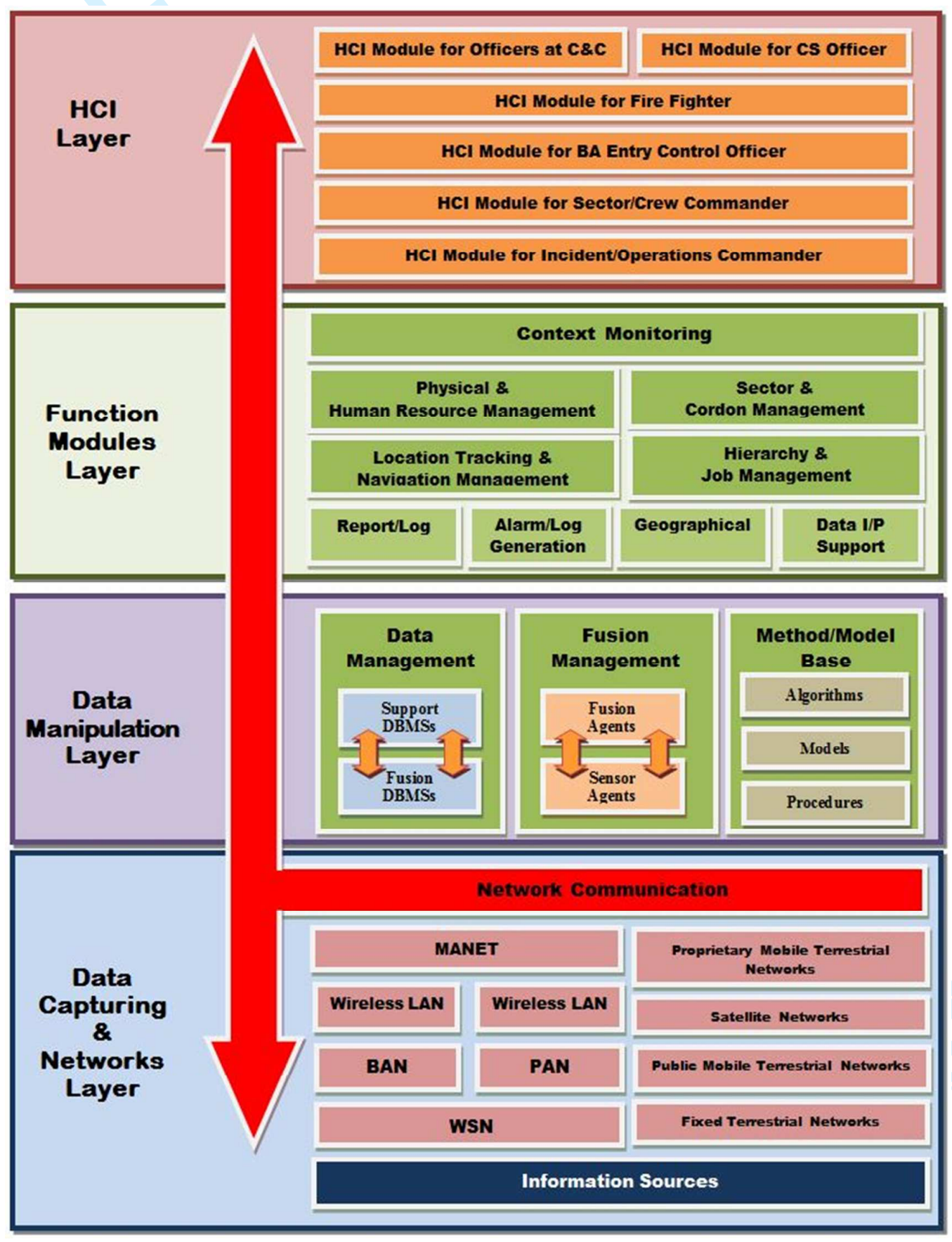

Figure 3. Conceptual ISA for Fire ER Operations 
Figure 3 illustrates the comprehensive ISA proposed for supporting emergency response to high risk built environment fires. As shown, this diagram elaborates the implemented components and services of the architectural layers focussing on supporting responses to a scenario involving a high-risk fire emergency response in a built environment. The architectural view, shown in figure 3, needs to be well understood by both the owners of the system as well as the systems architects because this is the basis for identifying and defining the components of future ER ISs. As explained above, this corresponds to an “owner's view” of an IS.

\section{Applicability and Validation of the Proposed Architecture}

The proposed conceptual architecture was subsequently used to develop a physical prototype of a system supporting fire fighters in the context of high-rise building fires (SafetyNet, n.d.). The physical prototype was tested at the Leicestershire fire training school. Two representatives each from the Police, Ambulance and Hospital Service and 20 firefighters representing different FRSs in the UK Midlands took turns to form a team of two fire fighters, one BAECO, one sector commander and one IC. These teams participated in a threehour field trial of the usability of the physical prototype. Participatory debriefing sessions were carried out at the end of the simulation, to obtain feedback from the fire fighters concerning the usability of the proposed type of a system. This session was video recorded, and researchers maintained field notes separately throughout the simulations. Subsequently recorded video footage and field notes were analysed using similar tools to those used during the requirements capturing phase.

Although a discussion of testing of the physical prototype is beyond the scope of this particular paper, the themes extracted from the testing of the physical prototype were very positive. In summary, all 20 participating fire fighters believed that the proposed type of systems are essential to improve their practice and will help to minimise fire fighter and public casualties. Although most of them proposed many new requirements and modification to the prototype, there was a clear indication of trust in using the type of system proposed. The fire fighters were very positive about the method and the definition of the information architecture and recognised this as a suitable system for supporting when responding to a wide range of infrastructure fire events. Although this particular validation was specifically conducted to test the usability and applicability of the prototype of the proposed system, the 
above feedback highlights the potentials to implement the conceptual architecture of the system outlined in the current paper and used as the primary design specification for building the physical prototype.

\section{Conclusion}

This paper has outlined the high-level conceptual architecture of a system for deploying human-computer interfaces in support of various fire ER roles. The ISA outlined defines essential components to be embedded within an overall IS.

\section{Implications for Theory and Practice}

There has previously been a very little literature which clearly explains the high-level systems architecture required to support fire ER. There has also been very little attention to producing an ISA, which is well understood by both system owners and system architects. Likewise, the majority of previous literature has proposed an ISA for either generic ER operations (for example: de Leoni et al., 2007; Meissner et al., 2006) or for generic ER purposes which are very different to fire ER (for example: Hwang et al., 2007; Lorincz et al., 2007; Wilson et al., 2005). Both of these shortfalls are addressed in the current research, by outlining a specific ISA for fire ER, in a manner which can be understood by system owners and system architects alike.

Pre-existing ISAs detailed in research literature appear to be less comprehensive and only focus on the needs of a few selected end users, or a few selected technologies. In contrast, the proposed ISA has been driven by a range of validated information, including the identified HCI needs of potential end users identified from two preliminary research. This combination has helped to define a comprehensive, and therefore more appropriate, ISA Importantly, the composition and functionality of each layer of the architecture proposed was only defined after considering the following aspects of the research context: 1) Overall enduser information needs, 2) end user information presentation and sharing needs, 3) existing opportunities and challenges for proven software and hardware technologies to address these end-user requirements, and 4) new software and hardware technology requirements reflecting the limitations technologies available at the time. Furthermore, the proposed high-level ISA for supporting fire fighters consists of four primary layers 1) Data Capture \& Networks, 2) Data Manipulation, 3) Function Modules and 4) Human Computer Interaction. This ISA was 
subsequently used to build a working physical prototype and later validated with the participation of end-users for it is usability. The findings of the validation study clearly justified that proposed ISA is suitable to build an IS capable of deploying human-computer interfaces to comprehensively address the specific needs of four of the key fire fighter job roles. The proposed ISA is, therefore, both more accurate and comprehensive for fire ER. Rather than taking a generic approach to the needs of an entire fire ER hierarchy, the proposed ISA outlines specific components which are essential for enhancing the SA of firefighters in different job roles during Fire ER.

The proposed, "owner's view", of the ISA architecture supporting specific fire fighter needs will make a significantly positive impact on the software engineering practices in crisis informatics. Participatory studies carried out with the support of potential end users has helped ensure that the proposed architectural view is well understood by both the owners of the system as well as the systems architects and therefore will have a significant influence in identifying and defining the components of their future ER ISs. This study therefore clearly outlines how the proposed ISA serves as a comprehensive platform for shared discussion among end users, system architects and designers, to understand and improve the essential components of an IS for fire ER. The proposed ISA may act as a conceptual benchmark for both clients and designers to a) compare and rank a system already available, or b) develop a context-specific system with high level of usability and trust among end-users. As a blueprint, this proposed ISA may guide system's architects to design technically comprehensive, architectural representations and support them work alongside with system developers to develop a more optimised IS for the FRS and other fire ER agencies.

By proposing an evidence-based ISA supporting fire ER, the outcomes of this paper fills a significant gap in the crisis informatics literature. It provides valuable input to both theory and methodological practice for the design and development of ISs for fire ER with the possibility of extending to other similar crises. This contribution is further justified by the findings of the systematic literature review of investigating emergency management information systems in last two decades (Dorasamy et al., 2013). In the literature reviewed, among nearly 50 systems supporting emergency management, SafetyNet was the only system that supports firefighters. The SafetyNet system was based on the ISA proposed in this paper. 


\section{Limitations and Implications for Further Research}

It is acknowledged that the selected scenarios may not represent all types of fire emergencies that occur in high risk built environments. Future research could consider incorporating a greater range of fire scenarios to help build a more robust understanding of the complex situations that can occur. The proposed ISA is an outcome of a participatory action research exclusively focused on fire risks in high-rise buildings and limited to the participation of emergency responders in the East Midlands region in the UK. However, most of the highest fire risk buildings in the UK are located in and around the London Metropolitan area. Further research, with the participation of FRS brigades and other fire ER agencies that are familiar with built environments having much higher levels of fires risk, could increase the applicability of the proposed type of ISA.

Validation studies, with a much broader participation driven by approaches similar to Delphi studies (Linstone \& Turoff, 2011) would also make a valuable contribution in the current research domain. Such approaches would provide an opportunity to explore how the proposed type of ISA suits different fire situations (tunnel fires, bush fires, airport fires, etc.) and in other local or international geographical locations. Such extensions of the current research would help better understand the levels of usability of proposed type of ISA in a much broader context. Extended validations could provide recommendations on how to improve the appropriateness of the layers of proposed architecture and embedded technologies to maximise potential benefits. Just as importantly, validation studies could provide recommendations for how an ISA can be implemented, accepted and trusted among a wider community of fire responders.

\section{References}

Berry, D., Usmani, A., Terero, J., Tate, A., McLaughlin, S., Potter, S., Trew, A., Baxter, R., Bull, M. and Atkinson, M. (2005), "FireGrid: Integrated emergency response and fire safety engineering for the future built environment" in Cox, S.J. and Walker, D.W. (Ed.s), Proceedings of the UK e-Science Programme All Hands Meeting in Nottingham, United Kingdom, 2005, Swindon, United Kingdom: Engineering and Physical Sciences Research Council.

Bevan, N. and Macleod, M. (1994), "Usability measurement in context", Behaviour and Information Technology, Vol.13 No. 1-2, pp. 132-145. 
Blasch, E., Kadar, I., Salerno, J., Kokar, M., Das, S., Powell, G., Corkill, D. and Ruspini, E. (2006), "Issues and challenges of knowledge representation and reasoning methods in situation assessment (level 2) fusion", Journal Of Advances In Information Fusion, Vol. 1 No. 2, pp.122-139.

Chong, C. and Kumar, S. P. (2003), "Sensor networks: Evolution, opportunities, and challenges", Proceedings of the IEEE, Vol.91 No.8, pp. 1247-1256.

Clegg, C. and Walsh, S. (2004), "Change management: Time for a change”, European Journal of Work and Organizational Psychology, Vol. 13 No. 2, pp. 217-239.

de Leoni, M., Mecella, M., de Rosa, F., Marrella, A., Poggi, A., Krek, A. and Manti, F. ( 2007), "Emergency management: From user requirements to a flexible P2P architecture" in Proceedings of the $4^{\text {th }}$ International ISCRAM Conference, Delft, Netherlands, 2007, Delft, Netherlands: ISCRAM, pp. 271-279.

Dorasamy, M., Raman, M. and Kaliannan, M. (2013), "Knowledge management systems in support of disasters management: A two-decade review", Technological Forecasting and Social Change, Vol.80 No.9, pp.1834-1853.

Endsley, M. R. (1995), “Toward a theory of situation awareness in dynamic systems”, Human Factors Journal, Vol. 37 No. 1, pp. 32-64.

Endsley, M. R., Bolte, B. and Jones, D. G. (2003), Designing for Situation Awareness: An Approach to Human-Centered Design, Taylor \& Francis, London.

Fraunhofer-Gesellschaft (2007), “About Fraunhofer-Gesellschaft”, available at: http://www.fraunhofer.de/en/about-fraunhofer/ (Accessed 4 September 2012).

Hall, D. L. and Llinas, J. (1997), “An introduction to multisensor data fusion”, Proceedings of IEEE, Vol.85 No. 1, pp. 6-23.

Hult, M. and Lennung, S. (1980), “Towards a definition of action research: A note and bibliography", Journal of Management Studies, Vol. 17 No. 2, pp. 241-250.

Hayes, G. R. (2011), “The relationship of action research to human-computer interaction", ACM Transactions on Computer-Human Interaction (TOCHI), Vol. 18 No. 3, article 15.

Hwang, Z., Uhm, Y., Lee, M., Kim, Y., Kim, G. and Park, S. (2007), “A context-aware system architecture for dealing with the emergency by the community service in 
apartment" in Proceedings of the Future Generation Communication and Networking (FGCN 2007), Jeju Island, Korea, 2007, Jeju Island, Korea: FGCN, pp. 402-407.

Jiang, X., Chen Y. N., Hong, I. J., Wang, K., Takayama, A. L. and Landay, A. J. (2004a), "Siren: Context-aware computing for firefighting" in Proceedings of the $2^{\text {nd }}$ International Conference on Pervasive Computing (Pervasive 2004), Vienna, Austria, 2004, pp. 87-105.

Jiang, X., Hong, I. J, Takayama, A. L. and Landay, A. J. (2004b), “Ubiquitous computing for firefighters: Field studies and prototypes of large displays for incident command" in Proceedings of the SIGCHI Conference on Human Factors in Computing Systems, Vienna, Austria, 2004, pp. 679-686.

Kwan, M. P. and Lee, J. (2005), “Emergency response after 9/11: The potential of real-time 3D GIS for quick emergency response in micro-spatial environments". Computers, Environment and Urban Systems, Vol. 29 No.2, pp. 93-113.

Klann, M. (2008), “Tactical navigation support for firefighters: The LifeNet Ad-Hoc SensorNetwork and Wearable System" in Proceedings of the Second International Workshop on Mobile Information Technology for Emergency Response (Mobile Response 2008), Bonn, Germany, 29-30 May 2008, pp. 41 - 56.

Linstone, H. A., \& Turoff, M. (2011), "Delphi: A brief look backward and forward", Technological Forecasting and Social Change, Vol. 78 No.9, pp.1712-1719.

Lorincz, K., Malan, D. J., Jones, T. R. F. F., Nawoj, A., Clavel, A., Shnayder, V., Mainland, J. Welsh, M. and Moulton, S. (2004), "Sensor networks for emergency response: Challenges and opportunities", Pervasive Computing, Vol. 3 No.4, pp. 16-23.

Madey, G. R., Szabo, G. and Barabasi, A. L. (2006), “WIPER: The Integrated Wireless Phone Based Emergency Response System" in Proceedings of the 6th International Conference on Computational Science (ICCS 2006), Reading, UK, 2006, pp. 417-424.

Maguire, M. (2001), “Methods to support human-centred design”, International Journal of Human-Computer Studies, Vol. 55 No. 4, pp. 587-634.

Maris, M. G. and Pavlin, G. (2006), "Distributed perception networks for crisis management" in Proceedings of the $3^{\text {rd }}$ International ISCRAM Conference, Newark, NJ, 2006, pp. 376-381. 
May, A., Mitchell, V., \& Piper, J. (2014), “A user centred design evaluation of the potential benefits of advanced wireless sensor networks for fire-in-tunnel emergency response", Fire Safety Journal, Vol. 63 No.2014, pp.79-88.

Meissner, A., Zhou, W., Putz, W. and Grimmer, J. (2006), “MIKoBOS - A mobile information and communication system for emergency response" in Proceedings of the $3^{\text {rd }}$ International ISCRAM Conference, Newark, NJ, 2006, pp. 92-101.

Microsoft (2015). “A technique for architecture and design”, available at https://msdn.microsoft.com/en-nz/library/ee658084.aspx (Accessed 19 November 2015).

Mullen, T., Avasarala, V. and Hall, D. L. (2006), "Customer-driven sensor management", IEEE Intelligent Systems, Vol. 21 No.2, pp. 41-49.

Nguyen, T. A. B., Englert, F., Farr, S., Gottron, C., Bohnstedt, D., and Steinmetz, R. (2015), "Hybrid communication architecture for emergency response-An implementation in firefighter's use case" in Proceedings of the 2015 IEEE International Conference on Pervasive Computing and Communication Workshops (PerCom Workshops), Pune, India, 2015, pp. 524-529.

Patton, M. Q. (2002), Qualitative Research and Evaluation Methods ( $3^{\text {rd }}$ ed.), Sage, London, United Kingdom.

Pavlin, G., Maris, M. and Nunnink, J. (2004), “An agent-based approach to distributed data and information fusion" in Proceedings of the IEEE/WIC/ACM Joint Conference on Intelligent Agent Technology (IAT 04), Beijing, China, 2004, pp. 466-470.

Pavlin, G. Oude, P. De, Maris, M., Nunnink, J. and Hood, T. (2007), “A distributed approach to information fusion based on causal probabilistic models: Technical report IAS-UVA07-03”, available at: http://staff.science.uva.nl/ poude/papers/pavlin07techrep.pdf (Accessed 12 October 2009).

Prasanna, R., Yang, L. \& King, M. (2013), "Human computer interaction for supporting fire emergency first responders. in Proceedings of the People and the Planet 2013Conference. Melbourne, Australia, 2013. Retrieved from http://globalcities.info/wp-content/uploads/2013/11/Human-Computer-Interaction-for-SupportingFire-Emergency-First-Responders.pdf 
Prasanna, R. (2010), “Information systems for supporting fire emergency response. Unpublished doctoral dissertation", Loughborough, United Kingdom: Loughborough University

Prasanna, R. K. R., Yang, L. and King, M. (2007), “Integrated information management system model for ER" in Proceedings of the 13th International Conference on Automation and Computing, Staffordshire, United Kingdom, 2007, pp. 59-64.

Roh, T. H. (2015). "Integrated command system for firefight safety in special disaster area", Fire Science and Engineering, Vol. 29 No. 6, pp.98-108.

SafetyNet (n.d.) , "SafetyNet field Trials", Retrieved from http://www.lboro.ac.uk/microsites/enterprise/safetynet/fieldtrial.html

Salerno, J. J., Hinman, M., and Boulware, D. (2004), "Building a framework for situation awareness" in Proceedings of the $7^{\text {th }}$ International Conference on Information Fusion, Stockholm, Sweden, 2004, pp. 219-226.

Salmon, P.M., Walker, G.H. and Stanton, N.A., 2016. "Pilot error versus sociotechnical systems failure: a distributed situation awareness analysis of Air France 447”, Theoretical Issues in Ergonomics Science, Vol. 17 No. 1, pp.64-79.

Scholz, M., Gordon, D., Ramirez, L., Sigg, S., Dyrks, T., \& Beigl, M. (2013). “A concept for support of firefighter frontline communication”, Future Internet, Vol. 5 No. 2, 113-127.

Sha, K., Shi, W., and Watkins, O. (2006). "Using wireless sensor networks for fire rescue applications: Requirements and challenges" in Proceedings of the 2006 IEEE International Conference Electro/information Technology, East Lansing, MI, 2006 , pp. 239-244.

Sowa, J. F. and Zachman. J. A. (1992), "Extending and formalizing the framework for information systems architecture", IBM Systems Journal, Vol. 31 No. 3, pp. 590-616.

Stanton, N. A., Salmon, P. M., Walker, G. H., Baber, C. and Jenkins, D. P. (2005), Human Factors Methods: A practical Guide for Engineering and Design, Ashgate, Aldershot, UK.

Strauss, A. and Corbin, J. (2008). Basics of Qualitative Research. Techniques and Procedures for Developing Grounded Theory ( $3^{\text {rd }}$ ed.), Sage, London, United Kingdom. 
Twidale, M., Randall, D. and Bentley, R. (1994), "Situated evaluation for cooperative systems" in Proceedings of the 1994 ACM conference on Computer supported cooperative work, Chapel Hill, NC, pp. 441-452.

White, C., Plotnick, L., Kushma, J. and Hiltz, S. R. (2009), “An online social network for emergency management", International Journal of Emergency Management, Vol. 6 No. 3, pp. 369-382.

Wilson J, Steingart, D., Romero, R., Reynolds, J., Mellers, E., Redfern, A., Lim, L., Watts, W., Patton, C., Baker, J. and Wright, P. (2005), "Design of monocular head-mounted displays for increased indoor firefighting safety and efficiency" in Proceedings of the Conference of SPIE: Helmet- and Head-Mounted Displays X: Technologies and Applications, Orlando, FL, 2005, pp. 103-114.

Wilson, J., Bhargava, V., Redfern, A. and Wright, P. (2007), “A wireless sensor network and incident command interface for urban firefighting" in Proceedings of the 4th Annual International Conference on Mobile and Ubiquitous Systems (MobiQuitous 2007): Computing, Networking \& Services, Philadelphia, PA, 2007, pp. 1-7.

Wooldridge, M. J. (2009), An Introduction to Multiagent Systems ( $2^{\text {nd }}$ ed.), John Wiley \& Sons, Sussex, United Kingdom.

Upadhyay, R., Pringle, G., Beckett, G., Potter, S., Han, L., Welch, S., Usmani, A. and Torero, J. (2008), "An architecture for an integrated fire ER system for the built environment" in Proceedings of the $9^{\text {th }}$ IAFSS International Symposium on Fire Safety Science, Karlsruhe, Germany, 2008, pp. 427-438.

Yang, L., Prasanna, R. and King, M. (2015). “GDIA: Eliciting information requirements in emergency first response”. Requirements Engineering, Vol.20 No.4, 345-362.

Yang, L., Yang, S. H., and Plotnick, L. (2013). "How the internet of things technology enhances emergency response operations", Technological Forecasting and Social Change, Vol. 80 No. 9, 1854-1867.

Zachman, J. A. (1987), "Framework for information systems architecture", IBM Systems Journal, Vol. 26 No.3, pp. 276-292. 


\begin{tabular}{|c|c|c|c|}
\hline Location & Systems & Network & $\begin{array}{l}\text { Communication } \\
\text { Technology/Protocol }\end{array}$ \\
\hline \multirow[t]{4}{*}{$\begin{array}{l}\text { Incident Premise- } \\
\text { Internal }\end{array}$} & \multirow[t]{2}{*}{$\begin{array}{l}\text { Responders Systems } \\
\text { deployed on to the Body } \\
\text { of the Responders }\end{array}$} & $\begin{array}{l}\text { Body Area Network } \\
\text { (BAN) for responders }\end{array}$ & $\begin{array}{l}\text { - } \text { Bluetooth } \\
\text { - } \quad \text { Ultra Wide Band (UWB) } \\
\text { digbee within the BAN } \\
\text { - Zigbee to get connected } \\
\text { to all other external } \\
\text { networks }\end{array}$ \\
\hline & & $\begin{array}{lr}\text { Personnel } & \text { Area } \\
\text { Network } & \text { (PAN) } \\
\text { responders } & \end{array}$ & • $\quad$ Zigbee \\
\hline & \begin{tabular}{lrr} 
Intelligent & \multicolumn{2}{r}{ Building } \\
Systems (Capable of \\
providing access to \\
Sprinkler, CCTV, Lighting, \\
Security Access and \\
Contextual Data) \\
\end{tabular} & LAN & - $\quad$ Wi-Fi \\
\hline & Contextual Data Systems & $\begin{array}{l}\text { Self-configurable } \\
\text { WSN }\end{array}$ & - Zigbee \\
\hline $\begin{array}{l}\text { Incident Premise } \\
\text { - Nearby External }\end{array}$ & $\begin{array}{lr}\text { Onsite Incident } & \text { Command } \\
\text { Management } & \text { System/ } \\
\text { Mobile } & \text { Emergency } \\
\text { Management } & \text { Data } \\
\text { Systems/Unmanned } & \text { Arial } \\
\text { Vehiclerrarger } & \text { Emergency } \\
\text { Management Systems }\end{array}$ & $\begin{array}{l}\text { Mobile Ad-hoc } \\
\text { Network (MANET) ( } \\
\text { Combination of Ad- } \\
\text { hoc WAN/LAN and } \\
\text { WSN) }\end{array}$ & $\begin{array}{ll}\text { - } & \text { Ad-hoc Combination of } \\
& \text { GSM/3G/4G(GMS } \\
& \text { Protocols) } \\
\text { - } & \text { WiMax (Non GSM) } \\
\text { - } & \text { Satellite } \\
\text { - } & \text { Wi-Fi } \\
\text { - } & \text { Bluetooth }\end{array}$ \\
\hline \multirow[t]{2}{*}{$\begin{array}{l}\text { Moving } \\
\text { Responder } \\
\text { Vehicles }\end{array}$} & \multirow[t]{2}{*}{$\begin{array}{lr}\text { Mobile } & \text { Emergency } \\
\text { Management } & \text { Data } \\
\text { Systems } & \end{array}$} & $\begin{array}{l}\text { Mobile Terrestrial } \\
\text { Network }\end{array}$ & $\begin{array}{ll}\text { - } & \mathrm{GSM} / 3 \mathrm{G} / 4 \mathrm{G} \\
\text { - } & \text { WiMax } \\
\text { - } & \text { Satellite } \\
\end{array}$ \\
\hline & & $\begin{array}{l}\text { Airwave Emergency } \\
\text { Network }\end{array}$ & $\begin{array}{ll}- & \text { Proprietary Terrestrial } \\
& \text { Trunked Radio (TETRA) }\end{array}$ \\
\hline $\begin{array}{l}\text { Regional } \\
\text { Command Centre }\end{array}$ & $\begin{array}{l}\text { Fire Emergency Command } \\
\text { Centre System }\end{array}$ & LAN & - Wi-Fi \\
\hline \multirow{2}{*}{$\begin{array}{l}\text { Fire Station/Third } \\
\text { Party } \\
\text { Expert/Police/Loc } \\
\text { al } \\
\text { Government/Envi } \\
\text { ronment } \\
\text { Agency/Water } \\
\text { Supplier/Hospital } \\
\text { /Ambulance } \\
\text { Service Control }\end{array}$} & \multirow[t]{2}{*}{$\begin{array}{l}\text { Emergency Management } \\
\text { Systems/ News, Weather, } \\
\text { Traffic and Metropolitan } \\
\text { CCTV Systems }\end{array}$} & LAN & - Wi-Fi \\
\hline & & $\begin{array}{ll}\text { Fixed } & \text { Terrestrial } \\
\text { Networks } & \end{array}$ & \begin{tabular}{ll|} 
- & DSL/ADSL/Fibre Optic \\
- & Satellite
\end{tabular} \\
\hline
\end{tabular}

Table 1. Components and Technologies for Data Capture and Networks 


1
2
3
4
5
6
7
8
9
10
11
12
13
14
15
16
17
18
19
20
21
22
23
24
25
26
27
28
29
30
31
32
33
34
35
36
37
38
39
40
41
42
43
44
45
46
47
48
49
50
51
52
53
54
55
56
57
58
59
60




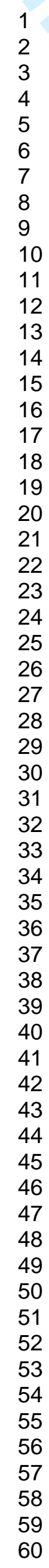




\section{Reply to the comments from the Associate Editor}

1) Introduction section is extensively lengthy. Have you by mistake added the literature review with the introduction section?

Previously we have discussed our literature under the introduction heading. In this revised version we have included a brief introduction and then moved all the literature under a new heading Literature Review.

2) You state in abstract that this study has built on the outcomes of two previous preliminary studies on information and human-computer interaction needs of core fire fighter job roles. But this is not clearly stated within the main body of the paper. May be you need to explicitly state the preliminary studies in separate subsections.

We have included brief description about the two studies in the methods section (highlighted in yellow)

3) Method section is too verbose with not sub-sections or figures or tables. Is there a way to bring out the methodology of this research more explicit?

In this revision we have introduced subheadings (highlighted in yellow) to reduce the level of abstraction and have also removed some of the text.

4) The results are too descriptive. Is there a better way to present the findings?

As explained in the results section it is paramount for us to introduce the four main layers of the architecture as those layers are core outcomes. As we expect to provide some guidance for the system designers to understand the functionality and link between these 
layers, it is very important for us to elaborate the structure and the contents of the four layers. Whenever possible we have tried to include some level of visualization using figures and tables to cut down the text (e.g. graphical representation of the Networks layer and table for technological components). However we could realise that amount of text used for the data Manipulation layer and HCI layers is somewhat lengthier and therefore in this new version we removed some of the text from those two subsections. However, we believe that it is very important for us to keep the remaining description communicate the components and functionality of the proposed architectural layers to our readers.

5) Clearly state in separate sub-sections under conclusion implications to theory and practice, limitations and future research recommendations/avenues.

We have included the subheadings in the Conclusions section as highlighted in yellow 